\title{
Urotensin receptor antagonist palosuran attenuates cyclosporine-a-induced nephrotoxicity in rats
}

\author{
Murat Olukman ${ }^{1, A, D}$, Cenk Can ${ }^{1, C}$, Deniz Coşkunsever ${ }^{1, B}$, Yiğit Uyanikgil ${ }^{3, B}$, \\ Türker Çavuşoğlu' ${ }^{2, B}$, Eser Sözmen ${ }^{2, B}$, Soner Duman ${ }^{3, E}$, Fatma Gül Çelenk ${ }^{2, C}$, Sibel Ülker, ${ }^{1, D, F}$ \\ ${ }^{1}$ Department of Medical Pharmacology, Faculty of Medicine, Ege University, Izmir, Turkey \\ ${ }^{2}$ Department of Histology and Embriology, Faculty of Medicine, Ege University, Izmir, Turkey \\ ${ }^{3}$ Department of Medical Biochemistry, Faculty of Medicine, Ege University, Izmir, Turkey \\ ${ }^{4}$ Department of Nephrology, Faculty of Medicine, Ege University, Izmir, Turkey \\ ${ }^{5}$ Department of Medical Genetics, Faculty of Medicine, Ege University, Izmir, Turkey \\ A - research concept and design; $\mathrm{B}$ - collection and/or assembly of data; $\mathrm{C}$ - data analysis and interpretation; \\ $D$ - writing the article; $E$ - critical revision of the article; $F$ - final approval of the article
}

\section{Address for correspondence \\ Murat Olukman}

E-mail: murat.olukman@ege.edu.tr

\section{Funding sources}

None declared

\section{Conflict of interest}

None declared

Received on May 22, 2018

Reviewed on August 17, 2018

Accepted on February 18, 2019

Published online on September 13, 2019

\section{Cite as}

Olukman M, Can C, Coșkunsever D, et al. Urotensin receptor antagonist palosuran attenuates cyclosporine-a-induced nephrotoxicity in rats. Adv Clin Exp Med. 2019;28(10):1393-1401. doi:10.17219/acem/104544

DOI

10.17219/acem/104544

\section{Copyright}

Copyright by Author(s)

This is an article distributed under the terms of the

Creative Commons Attribution Non-Commercial License

(http://creativecommons.org/licenses/by-nc-nd/4.0/)

\begin{abstract}
Background. Cyclosporine-A (CSA) is widely used for immunosuppressive therapy in renal transplantation. Nephrotoxicity is the main dose-limiting undesirable consequence of (SA. Urotensin II (U-II), a novel peptide with a powerful influence on vascular biology, has been added to the list of potential renal vascular regulators. Upregulation of the urotensin receptors and elevation of plasma U-II levels are thought to possibly play a role in the etiology of renal failure.
\end{abstract}

Objectives. The present study examines this hypothesis by evaluating renal function and histology with regard to the potential role of U-II and its antagonist, palosuran, in the pathogenesis of CSA-induced nephrotoxicity in rats.

Material and methods. Male Sprague-Dawley rats were treated with CsA (15 mg/kg, for 21 days, intraperitoneally) or (sA + palosuran (300 mg/kg, for 21 days). Renal function was measured and histopathology, U-II immunostaining and protein detection with western blotting of the kidneys were performed.

Results. Cyclosporine-A administration caused a marked decline in creatinine clearance (Ccr). Fractional sodium excretion ( $\mathrm{FE}_{\mathrm{Na}}$ ) tended to increase in the CSA-treated rats. Plasma U-II levels decreased in the CSAtreated rats. Cyclosporine-A treatment resulted in a marked deterioration in renal histology and an increase in the expression of U-II protein in the kidneys. Palosuran's improvement of renal function manifested as a significant decrease in serum creatinine levels and a significant increase in urine creatinine levels, resulting in a marked increase in Ccr. Palosuran produced a significant normalization of kidney histology and prevented an increase in U-II expression.

Conclusions. Cyclosporine-A-induced renal impairment was accompanied by an increase in U-II expression in kidneys and a contrary decrease in systemic $\mathrm{U}-\|$ l levels. Palosuran improved the condition of rats suffering from renal dysfunction by preventing the decrease in renal U-II expression without affecting the systemic levels of U-II. The protective effect of palosuran in CsA nephrotoxicity is possibly independent of its U-II receptor antagonism.

Key words: nephrotoxicity, urotensin-II, cyclosporine-A, palosuran, experiment 


\section{Introduction}

Cyclosporine-A ( $\mathrm{CsA})$ is a calcineurine inhibitor that is widely used for immunosuppressive therapy in renal transplantation patients. ${ }^{1}$ However, clinical usage of this immunosuppressant is often restricted by its side effects. Nephrotoxicity is the main dose-limiting undesirable consequence of CsA treatment, which may lead to irreversible damage in both glomerular and tubular structures. Chronic CsA treatment causes functional and structural nephrotoxicity characterized by glomerular sclerosis, tubulointerstitial fibrosis and tubular atrophy, ${ }^{2}$ whereas acute CsA nephrotoxicity induces a reversible reduction of the glomerular filtration rate (GFR) and renal blood flow, which is thought to result from afferent arteriolar vasoconstriction. ${ }^{3}$ The initial vasoconstriction caused by CsA is related to the imbalance between various modulators of renal vascular tonus, such as the powerful vasodilators prostacyclin and nitric oxide $\mathrm{e}^{4,5}$ and/or the vasoconstrictor factors angiotensin II and endothelin. ${ }^{6}$

Recently, urotensin II (U-II), a novel peptide with potent influences on vascular biology, was added to the list of potential renal vascular regulators. This peptide has been defined as the most potent vasoconstrictor to date and is a ligand for the Gq protein U-II receptor (UTR), originally known as the GPR 14 receptor. ${ }^{7}$ Urotensin II and UTR are expressed in a large number of tissues and organs $^{8,9}$ and pharmacological studies have shown that U-II plays a potent vasoactive role in the cardiovascular system. ${ }^{10,11}$ In addition to its potent direct vascular actions, U-II contributes to the control of renal function $^{12-15}$ and, therefore, is involved in cardiorenal disease states. Upregulation of the UTR receptors and elevation of plasma U-II levels have been postulated to play a possible role in the etiology of renal failure, congestive heart failure, diabetes mellitus, and systemic and portal hypertension. ${ }^{16-18}$ This suggestion has led to the development of different UTR antagonists in recent years. ${ }^{19}$ Among these, the selective UTR antagonist palosuran (ACT-058362C;1-[2-(4Benzyl-4-hydroxy-piperidin-1yl)-ethyl]-3-(2-methyl-quinolin-4-yl)-urea sulfate) has been shown to display renoprotective properties with beneficial recruitment on both glomerular and tubulointerstitial damage in experimental models of renal failure. ${ }^{20,21}$ In rats with ischemic acute renal failure, acute administration of palosuran significantly attenuated renal glomerular and tubular dysfunction, prevented increases in serum creatinine concentration and lessened the decrease in GFR. ${ }^{21}$ In addition, it has been shown that chronic palosuran treatment prevented the progressive increase in albuminuria, renal dysfunction and tubular and tubulointerstitial lesions in diabetic rats. ${ }^{21}$

Given the potential renoprotective effects of palosuran, we sought to examine whether this UTR antagonist might be useful in providing protection against CsA-induced nephrotoxicity. The present study therefore examines this hypothesis by evaluating renal function and histology with regard to the potential role of U-II in the pathogenesis of CsA-induced nephrotoxicity in rats.

\section{Material and methods}

\section{Experiment design}

Male Wistar rats (Ege University Animal Center, Izmir, Turkey) weighing 240-270 g were used in the study in order to exclude the confounding effect of sex-dependent factors (i.e., fluctuation in estrogen/progesterone levels during the menstruation cycle). This hormone fluctuation may influence an experiment, including X-chromosome and female sex hormone levels. All rats were fed standard rat food and water ad libitum under controlled environmental conditions (12-hour light/dark photo-period and a room temperature of $21 \pm 2^{\circ} \mathrm{C}$ ). The rats were randomly assigned to 5 experimental groups of 6 animals each:

Group 1 (Control): received daily intraperitoneal (i.p.) injections of saline solution for 21 days;

Group 2 (CsA) received CsA (15 mg kg/day, i.p.) for 21 days $^{22}$;

Group 3 (CsA+palosuran) received CsA (15 mg kg/day, i.p.) + palosuran (300 mg/kg/day, orally) for 21 days $^{21}$;

Group 4 (Vehicle) received a CsA vehicle (40 mg of Cremophor EL dissolved in 33\% alcohol, i.p.) at volumes equivalent to corresponding CsA doses for 21 days;

Group 5 (Palosuran) received palosuran $(300 \mathrm{mg} / \mathrm{kg} /$ day, orally) with concomitant daily i.p. injections of saline solution for 21 days.

The CsA used was a commercially available, injectable preparation (Sandimmune-parenteral ${ }^{\circledR}$ ). Palosuran was dissolved in distilled water and administered directly into the stomach through an intragastric canulla.

\section{Functional studies}

One day prior to sacrifice at the end of the treatment period, the rats were kept separately in metabolic cages; urine samples were collected over a 24-hour period for electrolyte and clearance studies. At sacrifice, blood samples were obtained by direct intracardiac puncture under anesthesia and the kidneys were removed for further studies and rinsed in ice-cold physiological saline. The blood samples were immediately centrifuged at $4^{\circ} \mathrm{C}$ and the plasma samples were stored at $-70^{\circ} \mathrm{C}$ until the biochemical analysis was performed.

\section{Urine and plasma analysis}

The concentrations of creatinine, sodium and potassium in the urine and plasma were measured with enzymatic assay, as were the U-II levels. The creatinine clearance rate (Ccr), the fractional excretion of sodium and 
the renal failure index were calculated using standard methods. The Ccr was calculated using the following formula: $\mathrm{Ccr}=\mathrm{UV} / \mathrm{P} / 1440$, where $\mathrm{Ccr}$ is the clearance in $\mathrm{mL} / \mathrm{min}, \mathrm{U}$ is the 24-hour urinary concentration of creatinine in $\mathrm{mg} / \mathrm{dL}, \mathrm{V}$ is the 24-hour urine volume in $\mathrm{mL}$ and $\mathrm{P}$ is the plasma concentration of creatinine in $\mathrm{mg} / \mathrm{L}$. Whole-blood CsA levels were measured using a Cloned Enzyme Donor Immunoassay (CEDIA; Microgenics Corporation, Fremont, USA) using an automatic analyzer (Hitachi 912, Hitachi Ltd, Tokyo, Japan). Since the last dose of CsA was given $24 \mathrm{~h}$ prior to sacrifice, all CsA levels measured were trough concentrations (Co).

\section{SDS-PAGE electrophoresis and western blotting}

The kidney tissue was homogenized in lysis buffer (20 mM of Tris- $\mathrm{mCl}$, pH 7.5, $2 \mathrm{mM}$ of EGTA, $5 \mathrm{mM}$ of EDTA, $10 \mathrm{mM}$ of dithiothreitol, $0.5 \mathrm{mg} / \mathrm{mL}$ of aprotinin, $0.001 \mathrm{mg} / \mathrm{mL}$ of pepstatin, $0.001 \mathrm{mg} / \mathrm{mL}$ of leupeptin, and $0.5 \mathrm{mM}$ of PMSF) on ice, then centrifuged at 14,000 $\mathrm{rpm}$ at $4^{\circ} \mathrm{C}$ for $30 \mathrm{~min}$ to remove the insoluble pellet. Protein concentration in the supernatant was measured spectrophotometrically using the Lowry method. Sixty micrograms of protein were loaded on $8 \%$ SDS-PAGE gel. The resolved proteins were transferred to $0.2-\mu \mathrm{m}$ nitrocellulose membranes and the blots were blocked in $5 \%$ non-fat dried milk for $1 \mathrm{~h}$ at $25^{\circ} \mathrm{C}$ to saturate nonspecific protein binding. The membranes were incubated with primary antibodies (anti U-II; $20 \mathrm{uL}$, anti- $\beta$-aktin; 1:20,000; Abcam, Cambridge, UK) overnight at $4^{\circ} \mathrm{C}$. After extensive washing, the blots were incubated in horseradish peroxidase-linked secondary antibodies (antimouse IgG, 1:10,000 for actin; 1:3,000 for anti U-II) for $1 \mathrm{~h}$ at $25^{\circ} \mathrm{C}$. The blots were covered with an ECL Plus ${ }^{\circledR}$ chemiluminescence detection kit (Amersham Pharmacia, Piscataway, USA) and then exposed to X-ray film. The autoradiographs were analyzed with scanning densitometry with subtraction of the background counts measured outside loaded lanes, and the intensity of the signal was measured with image analysis software (Image Quant TL v2003, Amersham Biosciences, Piscataway, USA). The data is presented as the ratio of U-II band density to $\beta$-actin band density.

\section{Morphology}

When the rats were sacrificed, the kidneys were removed, dissected and immersed in 4\% buffered paraformaldehyde for $24 \mathrm{~h}$ at room temperature. The tissues were dehydrated in a gradual alcohol series (80-95-100\%) and embedded in paraffin. For light microscopy, the paraffin sections were cut into 5- $\mu \mathrm{m}$ thick slices in microtome (Leica RM 2145; Leica Camera AG, Wetzlar, Germany) and stained with hematoxylin and eosin ( $\mathrm{H} \& \mathrm{E})$ to characterize general cellular patterns.

\section{Immunohistochemistry}

Immunocytochemical staining was performed on 5- $\mu \mathrm{m}$ sections of the formaldehyde-fixed, paraffin-embedded renal tissue. The sections were stained at the same time to avoid possible variation over time. After deparaffinization in xylol and rehydration with distilled water, the sections were kept in a citrate buffer ( $0.3 \%$ citrate, $\mathrm{pH} 6.0)$ in a microwave oven at $90 \mathrm{~W}$ for $5 \mathrm{~min}$ and at $360 \mathrm{~W}$ for $15 \mathrm{~min}$. After washing the sections in phosphate-buffered saline (PBS), they were exposed to normal horse serum for 30 min to block nonspecific immunoglobulin transfer, followed by overnight incubation with anti-U-II primary antibody (dilution 1:1000) at $4^{\circ} \mathrm{C}$ in a humidified chamber (Abcam, KIMERA Medical, İstanbul). Endogenous peroxidase activity in the rat kidney was blocked with $\mathrm{H}_{2} \mathrm{O}_{2}\left(3 \%\right.$ in $\mathrm{H}_{2} \mathrm{O}$ for $10 \mathrm{~min}$ ). The sections were then incubated with a biotinylated horse-antimouse secondary antibody (1:200) for $30 \mathrm{~min}$ at room temperature and washed with horseradish peroxidase conjugated streptavidin for $30 \mathrm{~min}$. All sections were visualized with 3,3'-diaminobenzidine tetrahydrochloride $/ \mathrm{H}_{2} \mathrm{O}_{2}$. Finally, the sections were counterstained with Mayer's hemotoxylin, dehydrated in an increasing series of alcohol (95\% for $2 \mathrm{~min}$ and $100 \%$, for $2 \mathrm{~min} \times 3$ ) and kept in xylol for 2 min 3 times just before being mounted in Entellan. The stained sections were scanned with an Olympus BX-51 microscope (Olympus Corp., Tokyo, USA) and images were taken with an Olympus C-5050 digital camera (Olympus Corp.). The images were analyzed in Image-Pro Express v. 4.5.1.3 software (Media Cybernetics Inc., Cambridge, UK). All digital quantification (ImagePro Plus, v. 6.0, Media Cybernetics Inc.) and assessments were performed in a blinded manner. Tubular injury was graded (0-3) based on the presence of tubular atrophy and the presence/degree of isometric tubular vacuolization: $0-$ no changes present, grade $1-\leq 25 \%$ to $50 \%$ and grade $3->50 \%$ tubular injury involvement. Interstitial fibrosis was scored as a sign of architectural destruction: 0 - no changes present, grade $1-25 \%$, grade $2-26 \%$ to $50 \%$ and grade $3->50 \%$ tubular injury involvement. ${ }^{23}$

\section{Drugs and reagents}

The CsA (Sandimmune-parenteral ${ }^{\circledR}$ ) was a kind gift from Novartis (Istanbul, Turkey). The palosuran was obtained from Actelion Pharmaceutical (Allschwil, Switzerland). All reagents used for western blotting and immunohistochemistry were of analytical grade.

\section{Data analysis}

The results are expressed as mean \pm standard error of the mean (SEM) of the groups. The differences between the means of the groups were assessed by one-way analysis of variance (ANOVA) with a subsequent Tukey's test. Associations between different variables were determined 
with linear regression analysis and Spearman's correlation coefficient was calculated between these variables. Results were considered significantly significant when $\mathrm{p}<0.05$.

\section{Results}

\section{Effects of CsA and palosuran on urine and serum output}

The biochemical parameters of all experimental groups are summarized in Table 1. Injection of CsA at a dose of $15 \mathrm{mg} / \mathrm{kg} /$ day for 21 days resulted in a whole-blood trough CsA concentration of 1,022.00 $\pm 97.10 \mathrm{ng} / \mathrm{mL}$. Palosuran treatment in the rats decreased the CsA concentration significantly $(822.08 \pm 115.72 \mathrm{ng} / \mathrm{mL}$; $\mathrm{p}<0.05)$. However, both concentrations were markedly higher than the targeted therapeutic concentration of CsA

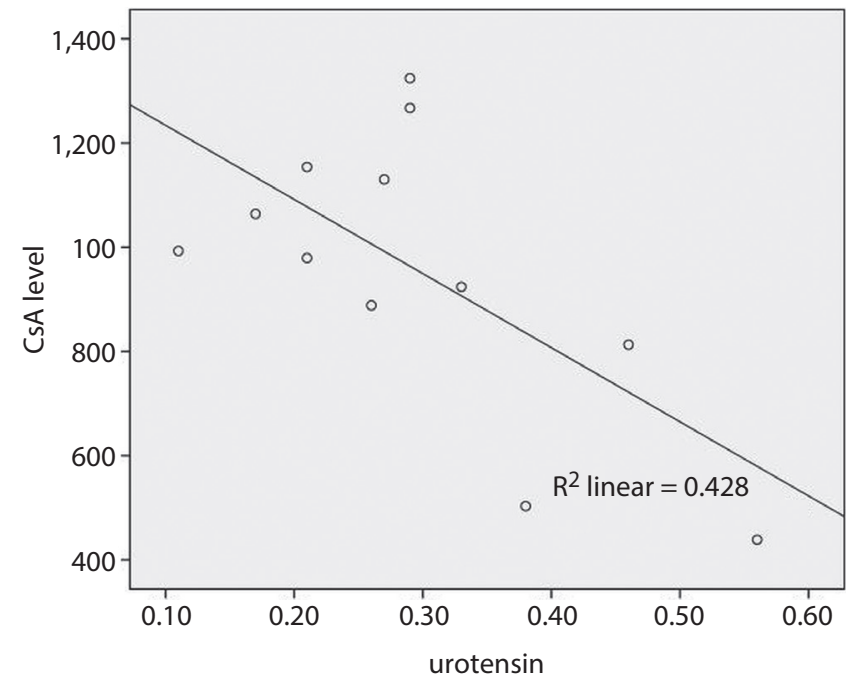

Fig. 1. Correlation between serum urotensin-II (U-II) and cyclosporine-A (CsA) levels. Spearman's rank correlation test revealed a correlation between serum $U$-II levels and CsA levels $\left(R^{2}=0.428\right)$
(250-400 $\mathrm{ng} / \mathrm{mL}$ ), indicating that the dosage used in our study maintained toxic trough concentrations. ${ }^{24}$ Cyclosporine-A administration caused a marked deterioration of renal function in the rats, characterized by a significant decline in Ccr with a concomitant increase in serum creatinine levels. Fractional sodium excretion $\left(\mathrm{FE}_{\mathrm{Na}}\right)$ tended to increase in the CsA-treated rats; however, the difference was not statistically significant. No effect of CsA was found on the other renal functional parameters compared to the control group. The vehicle of CsA did not significantly alter any of the parameters, either.

Administration of palosuran along with CsA led to an improvement in renal function, manifested as a significant decrease in serum creatinine levels and a significant increase in urine creatinine levels, resulting in a marked increase in $\mathrm{Ccr}$. However, $\mathrm{FE}_{\mathrm{Na}}$ showed a noteworthy decrease in these animals.

Palosuran caused no significant changes in the parameters tested when given to the control rats. The serum and urine levels of $\mathrm{Na}$ and $\mathrm{K}$ were comparable among all groups.

Plasma U-II levels were significantly lower in the CsAtreated rats in comparison to the control rats (Table 1). However, there was no correlation between the measured serum levels of CsA and the plasma levels of U-II in the CsA-treated rats (Fig. 1). Concomitant administration of palosuran and CsA did not further lower the U-II levels. The palosuran-treated control rats also revealed no significant differences in terms of U-II levels when compared to the naïve controls.

When the correlation of serum U-II levels with each parameter used to validate renal function was calculated, only a negative correlation with serum creatinine level was found (Fig. 2).

\section{Histopathological changes of kidneys}

The photomicrographs of kidneys from all groups are shown in Fig. 3. The microscopic findings of vehicle-treated

Table 1. Biochemical parameters of experimental groups. Data is expressed as mean $\pm S E M ; n=6$ in each group

\begin{tabular}{|c|c|c|c|c|c|}
\hline Parameters & Control & CsA & CsA + palosuran & Vehicle & $\begin{array}{c}\text { Palosuran + } \\
\text { control }\end{array}$ \\
\hline Urine volume [mL/day] & $5.15 \pm 1.25$ & $4.27 \pm 0.85$ & $3.36 \pm 0.49$ & $5.11 \pm 1.23$ & $6.11 \pm 1.31$ \\
\hline Urine creatinine $[\mathrm{mg} / \mathrm{dL}]$ & $87.30 \pm 13.20$ & $68.58 \pm 9.39$ & $152.60 \pm 19.25^{*}$ & $78.87 \pm 11.72$ & $72.10 \pm 11.40$ \\
\hline Urine $\mathrm{Na}[\mathrm{mEq} / \mathrm{L}]$ & $104.62 \pm 16.75$ & $72.94 \pm 19.95$ & $63.00 \pm 8.26$ & $100.04 \pm 25.48$ & $86.60 \pm 14.51$ \\
\hline Urine $\mathrm{K}$ [mEq/L] & $165.86 \pm 22.70$ & $140.05 \pm 9.10$ & $189.13 \pm 28.68$ & $145.20 \pm 17.87$ & $180.51 \pm 22.91$ \\
\hline Serum creatinine $[\mathrm{mg} / \mathrm{dL}]$ & $0.62 \pm 0.03$ & $1.06 \pm 0.18^{*}$ & $0.65 \pm 0.03^{\#}$ & $0.54 \pm 0.03$ & $0.56 \pm 0.02$ \\
\hline Serum Na [mEq/L] & $139.70 \pm 0.52$ & $141.53 \pm 0.46$ & $140.70 \pm 0.65$ & $140.43 \pm 0.63$ & $142.0 \pm 0.86$ \\
\hline Serum $K[\mathrm{mEq} / \mathrm{L}]$ & $5.41 \pm 0.14$ & $5.84 \pm 0.22$ & $4.87 \pm 0.17$ & $5.46 \pm 0.12$ & $5.50 \pm 0.03$ \\
\hline $\mathrm{Ccr}[\mathrm{mL} / \mathrm{min} / 100 \mathrm{~g}$ body weight $]$ & $0.45 \pm 0.02$ & $0.19 \pm 0.03^{*}$ & $0.50 \pm 0.04^{\#}$ & $0.43 \pm 0.06$ & $0.43 \pm 0.05$ \\
\hline $\mathrm{FE}_{\mathrm{Na}}[\%]$ & $0.53 \pm 0.05$ & $0.71 \pm 0.12$ & $0.19 \pm 0.01^{*, \#}$ & $0.51 \pm 0.10$ & $1.64 \pm 0.12^{*}$ \\
\hline Plasma urotensin level [ng/mL] & $0.57 \pm 0.04$ & $0.30 \pm 0.04^{*}$ & $0.29 \pm 0.06$ & $0.50 \pm 0.04$ & $0.59 \pm 0.04$ \\
\hline
\end{tabular}

${ }^{*} \mathrm{p}<0.05$ when compared to the control group; ${ }^{*} \mathrm{p}<0.05$ when compared to the CsA group. CsA - cyclosporine; Ccr - creatinine clearance; $F E_{N a}$ - fractional sodium excretion. 


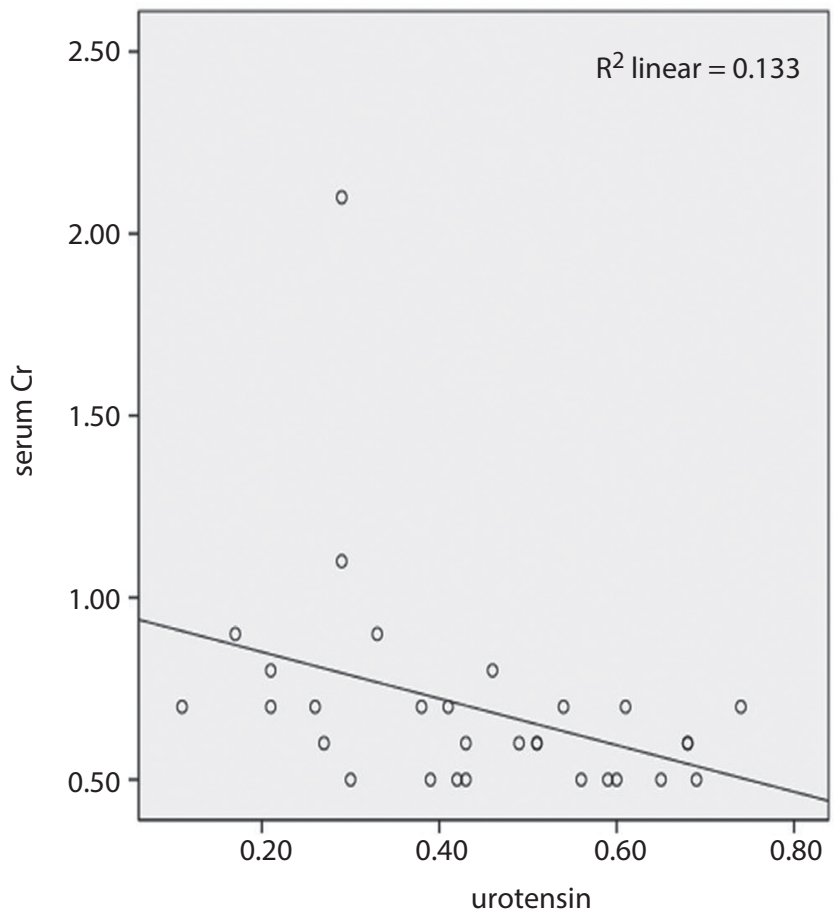

Fig. 2. Correlation between serum urotensin-II (U-II) and creatinine $(\mathrm{Cr})$ levels. Spearman's rank correlation test revealed a correlation between serum U-II levels and $\mathrm{Cr}$ levels $\left(R^{2}=0.133\right)$ rats showed essentially normal architecture. CyclosporineA treatment resulted in a marked deterioration in renal histology. The sections from the CsA-treated rat kidneys revealed derangements in both glomerular and tubular structures. Extensive mononuclear cell infiltration was observed in both perivascular and peritubular areas, mostly in the mid-cortex and the corticomedullary junctions. The cortical areas were characterized by diffuse peritubular capillary congestion and hemorrhagic foci. Vacuolization signs compatible with dilatation were observed in Bowman's space and the glomeruli. A foamy and vacuolated appearance of the parenchymal cell cytoplasm was noted in the distal and - more prominently - in the proximal tubules, and pyknotic nuclei were found in the tubular cells. Examination of the medullar sections revealed dilatation and tubular disintegration in all parts of the loop of Henle.

Simultaneous administration of CsA and palosuran produced a significant normalization of the kidney histology. Hemorrhagic foci and peritubular capillary congestion were seen less in the cortex and areas of mononuclear cell infiltration were sporadically found in the corticomedullary junction. The glomerular structures did not reveal signs of dilatation and the diameter of the glomerulus remained normal.

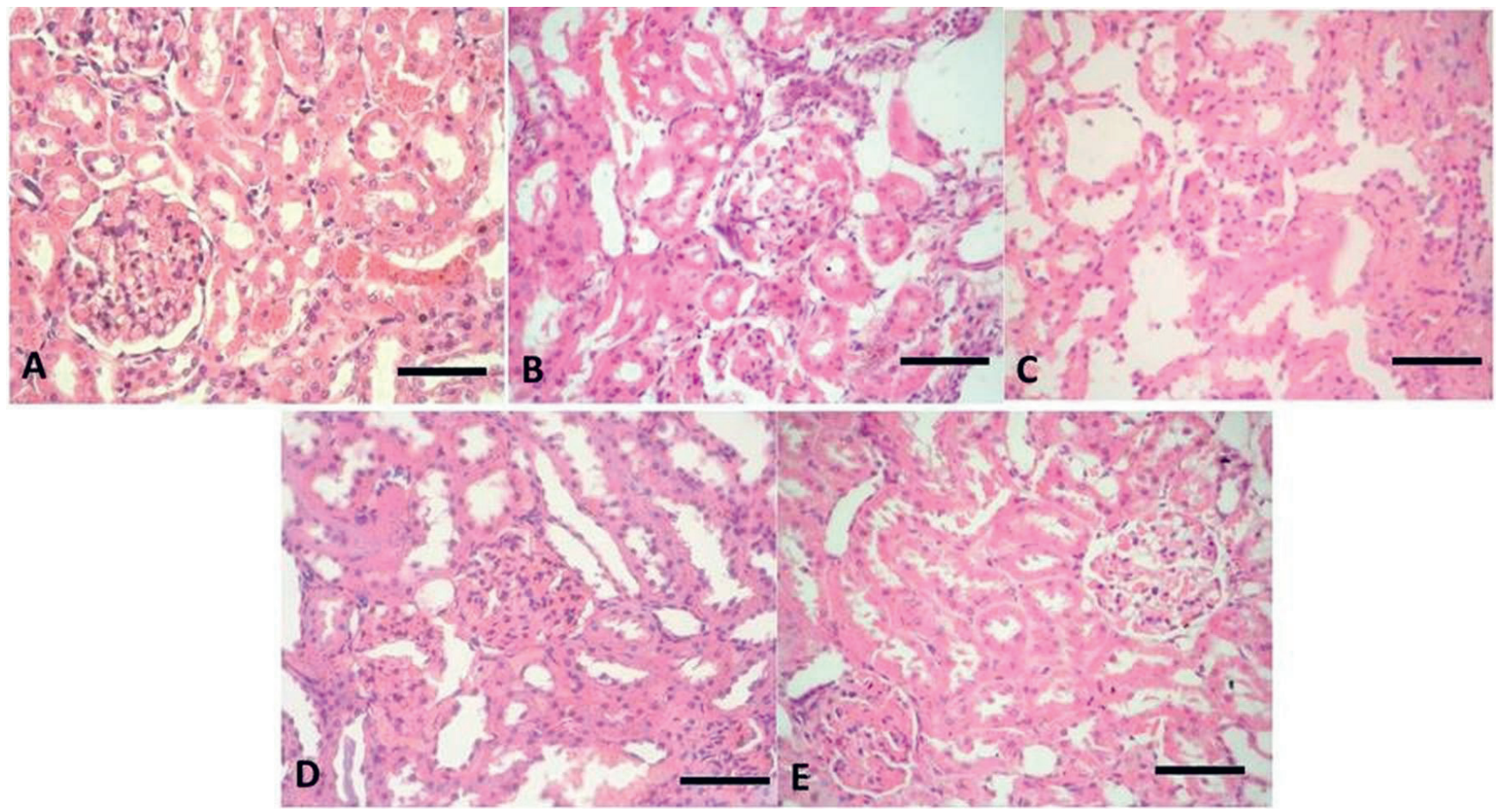

Fig. 3. Representative photomicrographs of histopathological findings in rat kidneys stained with H\&E, showing structural renal injury induced with cyclosporine-A (CsA) and the effect of palosuran treatment: (A) control, (B) CsA, (C) CsA + palosuran, (D) vehicle, and (E) palosuran-treated. Extensive mononuclear cell infiltration is visible in both the perivascular and peritubular areas. Peritubular capillary congestion and hemorrhagic foci are visible in the cortex, as well as signs of vacuolization compatible with dilatation in Bowman's space and glomeruli. The foamy appearance characteristic of vacuolated parenchymal cell cytoplasm is visible in the distal and proximal tubules. Pyknotic nuclei were characteristic in tubular cells. The simultaneous administration of palosuran and CSA produced a significant normalization of the kidney histology (C). Minimal hemorrhagic foci and peritubular capillary congestion are visible in the cortex, and scattered areas of mononuclear cell infiltration are present in the corticomedullary junction. The glomerular structures do not reveal signs of dilatation and the diameter of the glomerulus is normal. The scale bar is $50 \mu$ for $\times 100$ and $125 \mu$ for $\times 40$ magnification; $\mathrm{n}=4$ in each group. Representative experiments are shown 
Treatment of the rats with palosuran alone did not significantly affect kidney histology when compared to the untreated control kidneys; only minimal structural derangements were observed. The kidneys from the paloruran-treated rats revealed rare foci of congestion in perivascular and peritubular areas and sporadic areas of mononuclear cell infiltration in the corticomedullary junction. Minimal signs of dilatation and vacuolization in Bowman's capsules were observed.

\section{Immunohistochemical findings of the kidneys}

Incubation of kidney sections with an antibody against Urotensin II caused staining in different regions of the kidney. In control preparations, immunoreactivity was detected predominantly in the proximal tubules and it gradually decreased in the distal sections (Fig. 4), whereas no immunostaining was detected in the glomerular structure. Medullary collecting tubules and the loop of Henle were stained positively for U-II. Figure $4 \mathrm{~B}$ shows that U-II immunoreactivity was greatest in the CsA-treated rat kidneys. U-II immunostaining was most remarkable in the distal and proximal tubules, but also appeared in the glomerular region. Immunostaining of kidneys from both palosuran- and vehicle-treated control kidneys also showed staining in the tubular sections and slight staining in the glomerular sections, but immunoreactivity was considerably less when compared to the CsA group. The expression of U-II decreased dramatically with concomitant palosuran and CsA treatment in rat kidneys. The proximal and distal tubular sections from these rats showed a staining pattern similar to the control kidneys except for the minimal staining in the glomeruli.

\section{Effects of palosuran on U-II protein expression in renal tissue}

Cyclosporine-A treatment resulted in a significant increase in the expression of U-II protein in the kidneys ( $<<0.05$, Fig. 5). The addition of palosuran to CsA treatment significantly prevented the increase in U-II expression $(\mathrm{p}<0.05)$. The administration of a CsA vehicle or palosuran alone to the rats did not change U-II protein expression.

\section{Discussion}

In the current study, the CsA-treated animals showed a marked decline in creatinine clearance along with an elevation of serum creatinine levels. Histological examination of the kidneys from these rats revealed derangements in both the glomerular and tubular structures. These

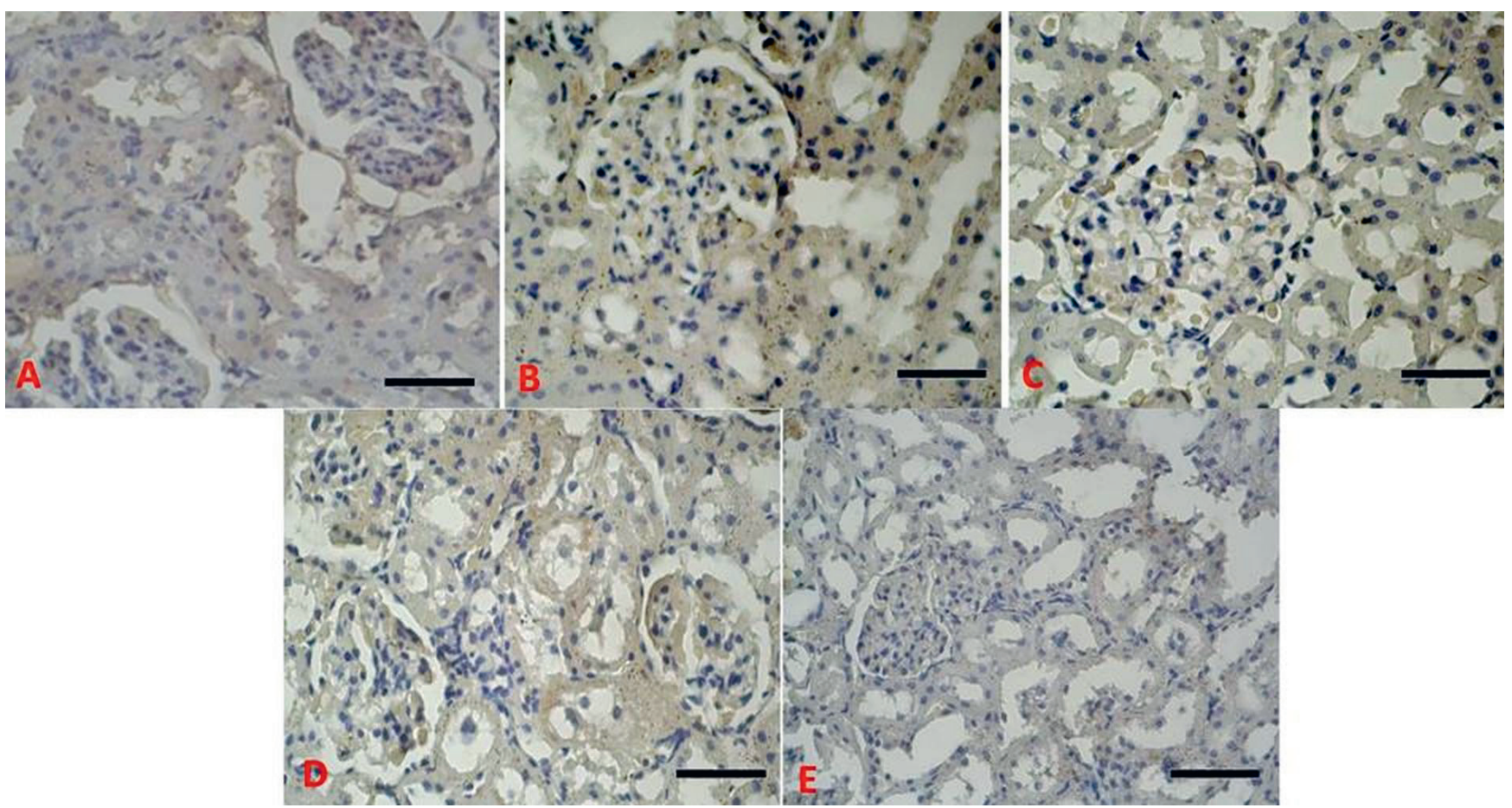

Fig. 4. Immunohistochemical localization of $U$-II in kidney sections of the experimental groups as follows: (A) control, (B) CsA, (C) CsA + palosuran, (D) vehicle, and (E) palosuran-treated. The CsA-treated animals show remarkable immunostaining in the distal and proximal tubules and in the glomerular region when compared to controls. The expression of U-\|l decreased abundantly with concomitant palosuran treatment in CsA-administered rat kidneys. The proximal and distal tubular sections from these rats showed a similar staining pattern with the control kidneys except for minimal staining in the glomerules. Immunostaining of kidneys from both palosuran- and vehicle-treated control kidneys also showed staining in the tubular area and faintly in the glomerular sections, though immunoreactivity was considerably less when compared to the CsA group. The scale bar is $50 \mu$ for $\times 100$ and $125 \mu$ for $\times 40$ magnification; $n=4$ in each group. Representative experiments are shown 


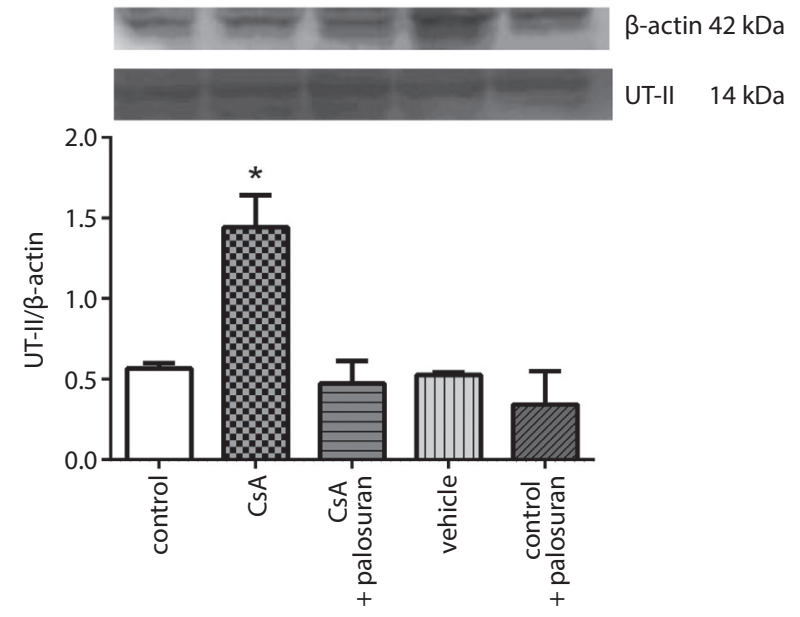

Fig. 5. Expression of urotensin II (U-II) protein in the kidneys of rats treated with cyclosporine (CSA) alone and in combination with palosuran for 21 days. The control group was composed of healthy rats receiving daily intraperitoneal (i.p.) injections of saline solution for 21 days. The vehicle group received i.p. injections of $40 \mathrm{mg}$ of Cremophor EL dissolved in 33\% alcohol at volumes equivalent to corresponding CsA doses for 21 days; ${ }^{*} p<0.05$ when compared to controls and ${ }^{*} p<0.05$ when compared to $\operatorname{Cs} A ; n=4$

findings are in agreement with the well-known pattern of acute CsA nephrotoxicity and they support previous reports on CsA-induced renal dysfunction and morphological changes. ${ }^{22}$ Alterations in renal hemodynamics and glomerular and/or tubular structures play important roles in CsA-induced renal dysfunction. ${ }^{25}$ CyclosporineA-induced nephrotoxicity is characterized by a marked reduction in renal blood flow and a reduction in glomerular filtration rate, which in turn leads to elevated serum creatinine levels and decreased serum $\mathrm{Ccr} .{ }^{26}$ Consistent with these reports, our findings mimicked the initial phase of CsA-induced renal complications.

The vasoconstrictor effect of CsA on renal vasculature is involved in chronic CsA nephrotoxicity as well. ${ }^{27}$ The major mechanism of CsA action on GFR is vasoconstriction in afferent arterioles through the mediation of contractile factors (i.e., angiotensin II and endothelin). ${ }^{26} \mathrm{We}$ have hypothesized that a newly identified modulator, U-II, may also contribute to CsA-induced nephrotoxicity and, if so, the selective UTR antagonist palosuran may be useful in preventing CsA-induced nephrotoxicity. Indeed, palosuran treatment showed a significant improvement in both functional and structural changes induced by CsA. It prevented a CsAinduced decrease in $\mathrm{Ccr}$, leading to a concomitant decrease in serum creatinine. Moreover, the morphological derangements in both the glomerular and tubular structures induced by CsA were attenuated by palosuran treatment.

This data agrees in part with previous data reporting the possible renoprotective potential of palosuran with beneficial effects on both glomerular and tubulointerstitial damage in renal ischemia/reperfusion ${ }^{20}$ and diabetes-induced renal injury. ${ }^{21}$ Palosuran increases renal blood flow without changing the filtration fraction, has a pre- and post-glomerular vasodilatator effect and delays the development of proteinuria and renal damage in diabetic rats, thus suggesting a possible role as a U-II receptor antagonist. $^{21}$

Although the impact of U-II on the kidneys is mainly mediated by its effects on vascular smooth muscle cells, its direct effect on the renal tubular cells and collecting ducts should also be considered. The immunolocalization of UTR in renal tubular cells suggests that U-II may act as an autocrine or paracrine regulator of the water and electrolyte transport in the tubular cells. ${ }^{18}$ Our immunohistological studies revealed increased U-II immunoreactivity in the CsA-treated rat kidneys. Urotensin II immunostaining was most notable in the distal and proximal tubules, though sporadic staining was noticed in the glomerular region as well. The expression of U-II decreased markedly in the rat kidneys treated concomitantly with palosuran and CsA. This finding also suggests a possible relationship between the increased U-II expression in kidneys and renal dysfunction. Hence, the expression of U-II mRNA in the kidney was enhanced in a model of chronic renal failure in rats. ${ }^{18}$ The principal site of U-II receptor expression in a rat kidney is the medulla, especially the tubular component of the kidney. Urotensin II was found mostly in the epithelial cells of tubules and ducts, with a greater density in the distal convoluted tubules in normal human kidneys; only focal immunoreactivity, however, was found in the endothelial cells of the glomeruli. ${ }^{18}$

Taken together, these findings suggest the possibility that although glomerular hemodynamic responses appear to dominate the effect of U-II on renal structures, the renal U-II system may also play a role in renal tubular function and electrolyte handling. In our study, palosuran caused a significant decrease in $\mathrm{FE}_{\mathrm{Na}}$, considering the natriuretic effect of U-II in CsA-treated rats at first glance. However, the studies on the role of U-II on renal electrolyte handling have provided conflicting results depending on the study protocols and rat species. For example, bolus injections of rat U-II in low concentrations leads to dose-related reductions in both GFR and sodium excretion rate, but only a modest reduction in GFR and no change in sodium excretion has been reported. ${ }^{28}$ Contrarily, U-II infusion caused a profound reduction in GFR accompanied by antidiuresis and antinatriuresis. ${ }^{29}$ Urotensin-II changes urinary electrolytes in a dose-dependent manner: at lower infusion rates it reduces electrolyte reabsorption. However, the fractional excretion of electrolytes was not altered by a UTR antagonist, urantide, suggesting that endogenous U-II may have little influence on tubular function in different rat strains. ${ }^{30}$

This last observation suggests the possibility that the effects of exogenously administered U-II do not necessarily mimic the exact effects of endogenously elevated levels of the mediator. The same might be true for antagonists as well, since different UTR antagonists exert different effects on the functional parameters of tubules regardless of the antagonistic capacity. ${ }^{31}$ For example, palosuran 
treatment caused an increase in sodium excretion in cirrhotic bile duct-ligated rats compared with untreated counterparts. $^{32}$ This natriuretic effect was accompanied by an increase in urine volume, an effect that was not observed in our study.

It seems that the effects of UTR antagonists on renal function do not necessarily have to be attributable to their U-II antagonistic properties alone, but the unintended effects of these antagonists should also be taken into account. ${ }^{33}$ Although palosuran exerted profound effects on both the functional and morphological parameters of the CsAtreated kidneys in our study, it did not cause significant changes on those parameters in the control rats. Thus, it is highly likely that the protective effect of palosuran in our model of CsA nephrotoxicity is independent of its U-II receptor antagonism. Indeed, palosuran inhibits U-II binding in membrane preparations with nearly equal potency as native U-II; however, its antagonistic activity is significantly less in intact cells. ${ }^{33}$ The dosing regimens used in the previous nephropathy models in which palosuran was reported to be effective ${ }^{20}$ were unable to inhibit rat U-II in vitro and the data from these studies does not convincingly demonstrate selective in vivo UTR blockade by palosuran. ${ }^{15}$ Moreover, recent studies have revealed that several actions of palosuran could not be replicated using another UTR antagonist, SB-701411. ${ }^{34,35}$ These observations taken together suggest a lack of UTR receptor affinity and an "offtarget" effect of palosuran in its renoprotective properties.

Cyclosporine-A treatment decreased mean serum U-II levels significantly and U-II levels demonstrated a negative correlation with serum creatinine levels, suggesting that the U-II system was potentially downregulated in the CsAtreated rats. However, the measured serum levels of CsA did not show any correlation with the plasma levels of U-II. On the other hand, although palosuran attenuated the derangements in functional and morphological parameters of CsA-induced renal dysfunction, it did not affect the decreased plasma U-II levels. These findings strengthen the hypothesis that the beneficial effect of palosuran observed in the present study was independent of its U-II receptor antagonism. It is well-known that there are differences in plasma U-II concentration between healthy subjects and patients with renal ${ }^{17}$ and heart failure. ${ }^{36,37}$ However, it has been controversial whether the U-II system in the kidney acts protectively or harmfully in kidney diseases. Although U-II levels are usually higher in patients than in controls, higher levels can also be found in renal transplant patients ${ }^{38}$ and they may correlate well with a decreased chance of adverse outcome, suggesting a protective role of U-II against cardiovascular events in renal disease states. ${ }^{38-40}$ Mosenkis et al. observed that plasma U-II concentrations were higher in controls than in subjects with end-stage renal disease undergoing hemodialysis or those with chronic renal disease, and that U-II correlated negatively with serum creatinine and positively with Ccr, suggesting a positive correlation between U-II concentration and renal function. ${ }^{38}$
The kidney is a major source of U-II, and urinary concentrations of U-II are significantly higher with renal tubular disease due to either reduced renal clearance or increased renal production. ${ }^{8}$ When acute symptoms arise, U-II is temporarily upregulated in order to repair the damage caused, but it later returns to its normal levels. This would explain how the upregulation of U-II is an inverse predictor of adverse clinical outcome in patients with acute coronary syndromes. ${ }^{39}$ Chronically high U-II levels, on the other hand, can lead to the development of several diseases, including cardiovascular disease and kidney disease. ${ }^{31}$

\section{Conclusions}

The present study demonstrated that exposure of healthy rats to toxic doses of CsA for 21 days resulted in a deterioration of both renal glomerular and tubular functions as well as a drop in Ccr. Cyclosporine-A-induced renal impairment was accompanied by an increase in U-II expression in kidneys and a contrary decrease in systemic U-II levels. The UTR antagonist palosuran mitigated renal dysfunction by preventing the decrease in renal U-II expression without affecting systemic levels of U-II. Its lack of an effect on the U-II system suggests that local U-II expression in the kidneys contributes to CsA-induced renal impairment. The protective effect of palosuran in our model of CsA nephrotoxicity is possibly independent of its U-II receptor antagonism, meaning that further research should be conducted to define the actual mechanisms of palosuran's action in various disease models.

\section{Ethics approval and consent to participate}

The project was approved by the Local Animal Care and Ethics Committee of Ege University, whose policies conform to the Guide for the Care and Use of Laboratory Animals published by the US National Institutes of Health (NIH Publication No. 85-23, revised 1996) and the present study was approved by the Institutional Animal Ethical Committee of Ege University (License No. 2010-26, 26/02/2010).

\section{References}

1. Bennett WM, DeMattos A, Meyer MM, Andoh T, Barry JM. Chronic cyclosporine nephropathy: The Achilles' heel of immunosuppressive therapy. Kidney Int. 1996;50(4):1089-1100.

2. Liptak P, Ivanyi B. Primer: Histopathology of calcineurin-inhibitor toxicity in renal allografts. Nat Clin Pract Nephrol. 2006;2(7):398-404; quiz following 404.

3. Barros EJ, Boim MA, Ajzen H, Ramos OL, Schor N. Glomerular hemodynamics and hormonal participation on cyclosporine nephrotoxicity. Kidney Int. 1987;32(1):19-25.

4. Perico N, Zoja C, Benigni A, Ghilardi F, Gualandris L, Remuzzi G. Effect of short-term cyclosporine administration in rats on renin-angiotensin and thromboxane A2: Possible relevance to the reduction in glomerular filtration rate. J Pharmacol Exp Ther. 1986;239(1):229-235. 
5. Bobadilla NA, Gamba G, Tapia E, et al. Role of NO in cyclosporin nephrotoxicity: Effects of chronic NO inhibition and NO synthases gene expression. Am J Physiol. 1998;274(4 Pt 2):F791-798.

6. Capasso G, Unwin R, Ciani F, et al. Inhibition of neutral endopeptidase potentiates the effects of atrial natriuretic peptide on acute cyclosporin-induced nephrotoxicity. Nephron. 2000;86(3):298-305.

7. Ames RS, Sarau HM, Chambers JK, et al. Human urotensin-II is a potent vasoconstrictor and agonist for the orphan receptor GPR14. Nature. 1999;401(6750):282-286.

8. Matsushita M, Shichiri M, Imai T, et al. Co-expression of urotensin II and its receptor (GPR14) in human cardiovascular and renal tissues. J Hypertens. 2001;19(12):2185-2190.

9. Maguire JJ, Kuc RE, Davenport AP. Orphan-receptor ligand human urotensin II: Receptor localization in human tissues and comparison of vasoconstrictor responses with endothelin-1. Br J Pharmacol. 2000;131(3):441-446.

10. Douglas SA, Naselsky D, Ao Z, et al. Identification and pharmacolog ical characterization of native, functional human urotensin-II receptors in rhabdomyosarcoma cell lines. Br J Pharmacol. 2004;142(6): 921-932.

11. Gardiner SM, March JE, Kemp PA, et al. Regional heterogeneity in the haemodynamic responses to urotensin II infusion in relation to UT receptor localisation. Br J Pharmacol. 2006;147(6):612-621.

12. Langham RG, Kelly DJ. Urotensin II and the kidney. Curr Opin Nephrol Hypertens. 2013;22(1):107-112.

13. Langham RG, Kelly DJ, Gow RM, et al. Increased expression of urotensin II and urotensin II receptor in human diabetic nephropathy. Am J Kidney Dis. 2004;44(5):826-831.

14. Totsune K, Takahashi K, Arihara Z, et al. Elevated plasma levels of immunoreactive urotensin II and its increased urinary excretion in patients with Type 2 diabetes mellitus: Association with progress of diabetic nephropathy. Peptides. 2004;25(10):1809-1814.

15. Tölle $M$, van der Giet M. Cardiorenovascular effects of urotensin II and the relevance of the UT receptor. Peptides. 2008;29(5):743-763.

16. Watanabe T, Arita S, Shiraishi Y, et al. Human urotensin II promotes hypertension and atherosclerotic cardiovascular diseases. Curr Med Chem. 2009;16(5):550-563.

17. Totsune K, Takahashi K, Arihara Z, Sone M, Ito S, Murakami O. Increased plasma urotensin II levels in patients with diabetes mellitus. Clin Sci (Lond). 2003;104(1):1-5.

18. Mori N, Hirose T, Nakayama T, et al. Increased expression of urotensin II-related peptide and its receptor in kidney with hypertension or renal failure. Peptides. 2009;30(2):400-408.

19. Douglas SA, Dhanak D, Johns DG. From 'gills to pills': Urotensin-II as a regulator of mammalian cardiorenal function. Trends Pharmacol Sci. 2004;25(2):76-85.

20. Clozel M, Binkert C, Birker-Robaczewska M, et al. Pharmacology of the urotensin-II receptor antagonist palosuran (ACT-058362; 1-[2(4-benzyl-4-hydroxy-piperidin-1-yl)-ethyl]-3-(2-methyl-quinolin-4$\mathrm{yl}$ )-urea sulfate salt): First demonstration of a pathophysiological role of the urotensin system. J Pharmacol Exp Ther. 2004;311(1):204-212.

21. Clozel M, Hess P, Qiu C, Ding SS, Rey M. The urotensin-II receptor antagonist palosuran improves pancreatic and renal function in diabetic rats. J Pharmacol Exp Ther. 2006;316(3):1115-1121.
22. Capasso G, Di Gennaro Cl, Della Ragione F, et al. In vivo effect of the natural antioxidant hydroxytyrosol on cyclosporine nephrotoxicity in rats. Nephrol Dial Transplant. 2008;23(4):1186-1195.

23. Takasu C, Vaziri ND, Li S, et al. Treatment with dimethyl fumarate attenuates calcineurin inhibitor-induced nephrotoxicity. Transplantation. 2015;99(6):1144-1150.

24. Jorga A, Holt DW, Johnston A. Therapeutic drug monitoring of cyclosporine. Transplant Proc. 2004;36(2 Suppl):396S-403S.

25. Nankivell BJ, Borrows RJ, Fung CL, O'Connell PJ, Allen RD, Chapman JR. The natural history of chronic allograft nephropathy. N Engl J Med. 2003;349(24):2326-2333.

26. Thomson SC, Tucker BJ, Gabbai F, Blantz RC. Functional effects on glomerular hemodynamics of short-term chronic cyclosporine in male rats. J Clin Invest. 1989;83(3):960-969.

27. Shihab FS, Yi H, Bennett WM, Andoh TF. Effect of nitric oxide modulation on TGF-beta1 and matrix proteins in chronic cyclosporine nephrotoxicity. Kidney Int. 2000;58(3):1174-1185.

28. Ovcharenko E, Abassi Z, Rubinstein I, Kaballa A, Hoffman A, Winaver J. Renal effects of human urotensin-II in rats with experimental congestive heart failure. Nephrol Dial Transplant. 2006;21(5):1205-1211.

29. Abdel-Razik AE, Forty EJ, Balment RJ, Ashton N. Renal haemodynamic and tubular actions of urotensin II in the rat. J Endocrinol. 2008; 198(3):617-624.

30. Song W, Abdel-Razik AE, Lu W, et al. Urotensin II and renal function in the rat. Kidney Int. 2006;69(8):1360-1368.

31. Tsoukas P, Kane E, Giaid A. Potential clinical implications of the urotensin II receptor antagonists. Front Pharmacol. 2011;2:38.

32. Trebicka J, Leifeld L, Hennenberg M, et al. Hemodynamic effects of urotensin II and its specific receptor antagonist palosuran in cirrhotic rats. Hepatology. 2008;47(4):1264-1276.

33. Behm DJ, McAtee JJ, Dodson JW, et al. Palosuran inhibits binding to primate UT receptors in cell membranes but demonstrates differential activity in intact cells and vascular tissues. Br J Pharmacol. 2008;155(3):374-386.

34. Albertin G, Casale V, Ziolkowska A, et al. Urotensin-II and Ull-receptor expression and function in the rat adrenal cortex. Int $\mathrm{J} \mathrm{Mol} \mathrm{Med.}$ 2006;17(6):1111-1115.

35. Spinazzi R, Albertin G, Nico B, et al. Urotensin-Il and its receptor (UT-R) are expressed in rat brain endothelial cells, and urotensin-II via UT-R stimulates angiogenesis in vivo and in vitro. Int J Mol Med. 2006;18(6):1107-1112.

36. Douglas SA, Tayara L, Ohlstein EH, Halawa N, Giaid A. Congestive heart failure and expression of myocardial urotensin II. Lancet. 2002; 359(9322):1990-1997.

37. Richards AM, Charles C. Urotensin II in the cardiovascular system. Peptides. 2004;25(10):1795-1802.

38. Mosenkis A, Kallem RR, Danoff TM, Aiyar N, Bazeley J, Townsend RR. Renal impairment, hypertension and plasma urotensin II. Nephrol Dial Transplant. 2011;26(2):609-614.

39. Khan SQ, Bhandari SS, Quinn P, Davies JE, Ng LL. Urotensin II is raised in acute myocardial infarction and low levels predict risk of adverse clinical outcome in humans. Int J Cardiol. 2007;117(3):323-328.

40. Zoccali C, Mallamaci F, Tripepi G, Cutrupi S, Pizzini P, Malatino L. Urotensin II is an inverse predictor of incident cardiovascular events in end-stage renal disease. Kidney Int. 2006;69(7):1253-1258. 